\title{
Price and Market Behavior in Phase II of the EU ETS: A Review of the Literature
}

\author{
Beat Hintermann*, Sonja Peterson ${ }^{\dagger}$, and Wilfried Rickels
}

\section{Introduction}

The European Union (EU) Emissions Trading Scheme (ETS) is a multinational cap-and-trade system $^{1}$ that has been operating for more than 10 years and is currently in its third phase (20132020). The EU ETS provides an institutional framework for market forces to determine the price of carbon emissions in energy-intensive industrial sectors in Europe. It is not only the central instrument for Europe's climate policy but also a globally observed experiment on whether emission abatement can be achieved efficiently. Recent initiatives aimed at linking the EU ETS during phase III with other emission-trading schemes (e.g., New Zealand, South Korea, and Switzerland) have bolstered hopes that the EU ETS is the precursor to a truly global carbon market.

Generally speaking, the goal of emissions trading is to achieve a given emissions target at least cost by equalizing marginal abatement costs across firms (e.g., Montgomery 1972; Tietenberg 1985). Profit-maximizing firms will reduce emissions as long as this is cheaper than purchasing allowances on the market and vice versa. The efficient allowance price is equal to the cost of

* Department of Economics, University of Basel, Peter Merian-Weg 6, 4002 Basel, Switzerland; e-mail: b.hintermann@unibas.ch.

${ }^{\dagger}$ Kiel Institute for the World Economy, Kiellinie 66, 24105 Kiel, Germany; e-mail: sonja.peterson@ifw-kiel.de.

† Kiel Institute for the World Economy, Kiellinie 66, 24105 Kiel, Germany; e-mail: wilfried.rickels@ifw-kiel.de.

We would like to thank Denny Ellerman, Charles Kolstad, Suzanne Leonard, Andrew and Frederick Jenkins, Torben Kruel, Ralf Martin, Claudio Marcantonini, Mirabelle Muûls, Ulrich J. Wagner, Aleksander Zaklan, and two anonymous referees for helpful comments and suggestions. Part of this research was conducted while Wilfried Rickels was a visiting scholar at the School of International Relations and Pacific Studies at the University of San Diego. Financial support has been provided by the German Research Foundation via Grant CP1108, QU357/3-1, and RI1833/2-1 and by the Fritz Thyssen Foundation via travel grant Az.50.13.0.016.

${ }^{1} \mathrm{~A}$ cap-and-trade system is a market-based approach to controlling pollution/emissions where the regulating authority sets an overall emissions cap, or limit. This cap is divided into allowances, which give the holder the right to emit one unit of emissions (e.g., 1 ton of carbon dioxide), and distributed among the market participants. Allowances can be traded freely, and every market participant is required to surrender one allowance per unit of verified emissions.

Review of Environmental Economics and Policy, volume 10, issue 1, Winter 2016, pp. 108-128 doi:10.1093/reep/rev015

Advance Access published on December 3, 2015

(C) The Author 2015. Published by Oxford University Press on behalf of the Association of Environmental and Resource Economists. All rights reserved. For Permissions, please email: journals.permissions@oup.com 
reducing emissions to one unit below the emissions cap, which is generally referred to as the market's marginal abatement cost. This means that efficient abatement decisions require reliable allowance prices that reflect all available information on the cost of reducing emissions to achieve the cap. The role of allowance prices in indicating whether emissions trading works (i.e., achieves the target at least cost) has spurred a sizeable literature on price formation for EU ETS allowances. This article, which is part of a symposium on the EU ETS, ${ }^{2}$ reviews the literature on allowance price dynamics and levels, focusing in particular on empirical analyses of phase II (2008-2012) of the EU ETS. Our review includes papers that cover a range of issues associated with allowance price determination. Given the size of the current literature and space limitations, this review could not be exhaustive. Instead we focus on contributions that provide new insights or are representative of a larger set of papers and their findings and ignore those that are only loosely related to allowance price formation. Where appropriate, we have also included papers that are themselves literature reviews. We generally gave preference to papers that we believe are based on the most rigorous and reliable methodological approaches currently available. In addition, we do not explicitly assess or compare the quality of these studies. Rather we let the studies speak for themselves and invite readers to examine these studies and draw their own conclusions.

The remainder of the article is organized as follows. We first provide background on the dynamics of allowance prices in phase II of the EU ETS, by first discussing how marginal abatement cost theory determines the fundamental factors that influence allowance prices and then reviewing the empirical evidence on allowance price dynamics, including studies explicitly addressing the role of uncertainty. However, price changes are only one factor in allowance price formation. We then focus on the price level, which is just as important but has received much less attention in the literature because of the lack of an observable counterfactual for business-as-usual (BAU) emissions. Finally, we suggest priorities for future research and offers some conclusions about how the EU ETS has performed from a market perspective.

\section{Allowance Price Dynamics}

In efficient markets, the allowance price will be determined by supply and demand. The supply of allowances is primarily determined by policy decisions such as the level of the emissions cap, linkages to other emission markets, and rules about banking and borrowing. Because supply decisions predominantly affect the price level, we focus on factors determining allowance demand here and discuss supply decisions in detail in the next section. We begin by presenting the fundamentals for allowance prices and then discuss the empirical literature that aims to measure the extent to which changes in these fundamentals affect the allowance price.

\section{Price Fundamentals}

The fundamentals that in theory determine the allowance price can be divided into those that determine BAU emissions and those that determine marginal abatement costs.

\footnotetext{
${ }^{2}$ The other articles in this symposium are Ellerman, Marcantonini, and Zaklan (2016), which introduces the symposium and provides an overview of the EU ETS, and Martin, Muûls, and Wagner (2016), which examines the impacts of the EU ETS at the firm level.
} 


\section{BAU emissions}

The main drivers of the demand for allowances are BAU emissions in the sectors covered by the EU ETS. These emissions are driven primarily by economic growth and the economy's energy efficiency and (carbon) emission intensity (i.e., emissions/gross domestic product [GDP]). In the short term, BAU emissions are also driven by weather variation through their impact on the demand for heating or cooling ${ }^{3}$ and on power generation from renewables (e.g., Considine 2000; Alberola, Chevallier, and Chèze 2008; Hintermann 2010). For example, Scandinavia experienced an exceptionally dry year in 1996. As a result, Danish carbon emissions almost doubled compared with 1996 levels because instead of importing carbon-free hydropower from Sweden and Norway, Denmark exported carbon-intensive coal-based power to those countries (Christiansen et al. 2005).

\section{Marginal abatement costs}

The second driver of allowance prices are the available abatement options and their costs. Based on survey data, Heindl and Löschel (2012) find that during phase II process optimization and investment in energy efficiency were the most popular abatement options. Because these investments affect the price level of allowances but not daily fluctuations, the literature focuses on fuel switching prompted by the change in the "merit order" of electricity generation (i.e., the order in which generators are brought on line, usually based on lowest cost) as the most relevant short-term abatement option (e.g., Christiansen et al. 2005; Kanen 2006; Bertrand 2014). Due to the structure of the electricity sector in Europe, fuel switching is expected to take place mainly between coal and gas.

Under perfect competition, power providers will base their supply bids on marginal generation costs. The cost of carbon emissions (i.e., the allowance price) should induce fuel switching between all available generators as long as the implicit abatement cost does not exceed the allowance price. This implicit abatement cost is known as the "fuel-switching" price (in Euro per ton carbon dioxide $\left.\left[\mathrm{CO}_{2}\right]\right){ }^{4}$

Fuel switching can take place either within a firm or across generators owned by different firms. Using data from eight European countries between 1978 and 2004, Pettersson, Söderholm, and Lundmark (2013) present evidence for fuel switching, notably in countries with a high proportion of gas, coal, and oil generation. In general, an increase in the gas/coal price ratio increases the fuel switching price, which should result in an increase in the allowance price, to the extent that fuel switching is indeed a relevant form of emissions abatement.

\section{Empirical Evidence on Allowance Price Formation in the EU ETS}

This subsection summarizes the empirical evidence for the influence of different factors on allowance price formation. ${ }^{5}$ The studies we examined vary both in their geographic coverage

\footnotetext{
${ }^{3}$ The relationship between temperature and energy demand is U-shaped (Bunn and Fezzi 2008), with temperatures below a certain threshold leading to an increase in energy demand for heating purposes and temperatures above a certain threshold leading to an increase in energy demand for cooling purposes.

${ }^{4}$ Formally, the fuel switching price is: $P_{f s}=\frac{\eta_{g a s} \cdot P_{g a s}-\eta_{\text {coal }} \cdot P_{\text {coal }}}{E_{\text {coal }}-E_{\text {gas }}}$, where $P_{\text {gas }}$ and $P_{\text {coal }}$ represent the gas and coal price (in Euro per MWh fuel), respectively, $\eta$ is the corresponding heat rate (in MWh fuel per MWh electricity), and E the emission factor (in $\mathrm{tCO}_{2}$ per MWh electricity).

${ }^{5}$ For an overview of the studies we examine in this section, see Appendix table 1.
} 
and with respect to the time periods covered, the selected price variables, and the representation of weather variables. This makes it difficult to directly compare the magnitude of the studies' results. Across all studies, economic activity and growth announcements, as well as the oil price, are found to positively influence allowance prices on an intraday, daily, weekly, and monthly basis. $^{6}$ In the discussion that follows, we examine the influence of gas, coal, and electricity prices, the influence of renewable energy supply, and the ability of allowance banking to smooth the shocks that result from these factors. We focus on evidence from phase II but refer to results from earlier years where appropriate. ${ }^{7}$

\section{Energy prices}

Across all of the studies that we reviewed, the natural gas price (if explicitly included) is found to have a positive and statistically significant effect on allowance prices. However, this is not the case for the coal price. Whereas Aatola, Ollikainen, and Toppinen (2013) find a negative influence of the coal price, Lutz, Pigorsch, and Rotfuß (2013) find a positive influence during certain periods. ${ }^{8}$ Koch et al. (2014) and Fell, Hintermann, and Vollebergh (2015) find the influence of the coal price to be insignificant. Empirical studies that use energy prices to explain allowance price dynamics commonly rely on one price to represent oil, gas, and coal. However, the coal market is still much less integrated than the gas and oil market, and power utilities might simply not face the same coal price in their decisions about fuel switching (Zaklan et al. 2012 and Schernikau 2010, respectively). Using a broad set of coal, gas, and oil prices, Rickels et al. (2015) confirm in particular that different coal price series explain different aspects of allowance price dynamics. Thus, the oversimplified assumptions concerning the European energy market that underlie the empirical studies may be at least partly responsible for the mixed results on the influence of energy prices. Moreover, not all studies include the electricity price in their analysis, which means that some of the coal price results could be explained by omitted variables.

The possibility that electricity, fuel, and allowance prices are jointly determined has motivated several authors to use cointegration analyses to examine the long-term relationship between energy and carbon prices. In contrast to methods where fuel prices are interpreted as predetermined fundamentals for the allowance price, in a cointegration analysis, all prices are allowed to be determined endogenously. Focusing exclusively on fuel and allowance prices, Creti, Jouvet, and Mignon (2012) find that fuel and allowance prices are cointegrated (i.e., share a common trend). However, they also find that the cointegration relationship appears to significantly explain allowance price dynamics only during certain periods of the second phase. Using monthly data, Koch et al. (2014) do not find cointegration between allowance and fuel prices. Rickels et al. (2015) emphasize that the identification of a cointegration relationship is sensitive to the specific fuel price series selected and argue that, conditional on the "right" combination of prices and estimation methodology, statistically significant

\footnotetext{
${ }^{6}$ There is no consensus on whether the influence of the oil price is due to it being a proxy for economic activity, natural gas prices, or (limited) fuel switching from oil to gas (Pettersson, Söderholm, and Lundmark 2013).

${ }^{7}$ See Zhang and Wei (2010) for a more detailed review of the various studies of allowance price dynamics during phase I.

${ }^{8}$ Using a Markov-switching regime, they find that the coal price has a significant positive influence in the first regime, but a negative influence in the second regime. However, the latter is significant only at the 10 percent level.
} 
cointegration can be found but might not (yet) necessarily represent an economically meaningful long-term relationship between allowance and fuel prices.

Studies that include the electricity price find more robust cointegration relationships between electricity, fuel, and allowance prices. ${ }^{9}$ However, including the electricity price requires a segmented approach to the EU ETS market because national power markets are not yet fully integrated across the EU. Fell, Hintermann, and Vollebergh (2015) use a multicountry framework to investigate cointegration between fuel, electricity, and allowance prices not only within but also between different electricity markets. They identify equilibrium relationships between electricity, allowance, and fuel prices, but these relationships differ across markets due to differences in fuel mixes in electric generation.

Delarue, Ellerman, and D'haeseleer (2010) argue that although fuel switching is likely to be observable during some hours of the day, it cannot be easily observed in the daily aggregated price series. Moreover, the time-series approach for identifying the influence of fuel prices on allowance price dynamics cannot capture all of the channels underlying fuel switching during the course of the day (i.e., different generators can substitute for one another at different times of the day). This issue may increase in importance as the demand for fossil-based generation decreases as more renewables enter the system.

\section{Renewable energy supply and weather variation}

To determine the impact of hydropower on allowance prices, Rickels et al. (2015) examine reservoir levels in Nordic countries and confirm their negative influence on allowance prices. ${ }^{10}$ Fell, Hintermann, and Vollebergh (2015) provide indirect evidence for this effect by finding that reservoir levels are negatively correlated with the electricity price, which, in turn, is positively cointegrated with the allowance price. This result is confirmed by Aatola, Ollikainen, and Toppinen (2013), who use Nordic reservoir levels to instrument for electricity prices, which are positively correlated with the allowance price. In contrast, Koch et al. (2014) find that the supply of hydropower has no significant influence on allowance prices. However, their data do not include hydropower provision in Scandinavia and focus on production rather than storage levels. $^{11}$

Rickels et al. (2015) find that short-term variation in wind-power provision in Germany, Denmark, and Sweden has no robust effect on the allowance price. In contrast, Koch et al. (2014) report a significant negative influence of wind and solar electricity supply (based on monthly data) in Austria, Belgium, France, Germany, Italy, Netherland, Portugal, and Spain. Lutz, Pigorsch, and Rotfuß (2013) include variations in daily temperature but find no significant influence on the allowance price. Rickels et al. (2015) and Koch et al. (2014) confirm this result using variations in electricity consumption to account for weather-driven demand variations. These results indicate that long-term changes (e.g., an increase in renewable capacity) affect the allowance price, whereas short-term shocks (e.g., due to weather) do not. This can be explained by allowance banking, to which we turn next.

\footnotetext{
${ }^{9}$ Examples include Bunn and Fezzi (2008) for the United Kingdom, Fell (2010) for the Nordic market, and Lo Prete and Norman (2013) for Germany.

${ }^{10}$ This was previously identified for phase I by Hintermann (2010) and Fell (2010).

${ }^{11}$ Although an increase in hydro generation can reflect either an increased supply of hydropower or an increased demand for all electricity, a larger-than-normal reservoir level clearly indicates an increase in supply in the medium-to-long run.
} 


\section{Banking of allowances}

Banking and borrowing allow for the smoothing of demand and supply variations of allowances over time. Shocks_ such as an increase in energy demand resulting from heating during a cold spell or an increase in energy supply resulting from a temporary surge in wind power-are likely to be canceled out by shocks of similar magnitude but opposite sign that occur at some point in the future. Such shocks are known as "mean-reverting"- that is, they are temporary deviations from a long-term average to which they will eventually return. Mean-reverting shocks do not affect the cumulative amount of abatement required to comply with the long-term emission cap. Thus, their effect on the allowance price depends on banking rules.

Hintermann (2010) and Bertrand (2014) show that in the absence of banking across phases, variations in price fundamentals translate into stronger variations in allowance prices at the end of a trading phase. This is because it is increasingly less likely that temporary shocks will be counteracted by a later shock of the opposite sign during the remainder of the phase. Since the beginning of phase II, there have been no restrictions on the transfer of allowances from one period to the next. Borrowing from the next phase is not allowed, but as long as a positive amount of allowances is banked from one period to the next, a shock that temporarily increases emissions can be countered by a reduction in the amount of banked allowances. In this sense, firms can "quasi-borrow" from the amount of allowances that they planned to bank. Given the oversupply of allowances in phase II, the borrowing constraint was not binding during the transition to phase III.

Banking and (quasi-)borrowing imply that marginal abatement cost theory applies to cumulative expected abatement costs rather than to the daily abatement decision because banking and borrowing should eliminate the impact of such shocks to the cumulative expected allowance demand because these shocks will cancel out over time. This is consistent with the results discussed previously. In contrast, Hintermann (2010) reports a significant relationship between weather shocks and allowance prices during phase I, when banking was not allowed.

\section{The Role of Uncertainty}

While the studies discussed so far show that observed fundamental factors appear to affect allowance prices (mostly as predicted by theory), their combined results indicate that only a certain fraction of allowance price dynamics can be explained and that the degree of explained variation varies significantly over time. ${ }^{12}$ Most important, these studies do not account for the uncertainty that characterizes various price determinants. In particular, future fuel prices and other observable allowance price drivers are uncertain; unforeseen demand variations mean that BAU emissions are also stochastic. This suggests that the allowance price should reflect the expectations of market participants about allowance scarcity, including the associated uncertainty. In this section, we first discuss studies that show that the selling and buying of allowances is driven not only by the present deterministic cost but also by future uncertain marginal abatement costs. Clearly, uncertainty varies over time, suggesting that to explain allowance price dynamics, it is important to consider different approaches for different periods (regimes).

\footnotetext{
${ }^{12}$ Most studies include dummy variables for certain dates to reflect that fundamental factors influence allowance prices differently through time, implying that different regimes can be defined for the behavior of market participants.
} 
Thus, we discuss this issue next. Finally, we discuss the carbon finance literature, which examines purely data-driven approaches.

\section{The option value of holding an allowance}

When a firm faces uncertain future abatement costs (e.g., resulting from uncertain BAU emissions), it can postpone its abatement decisions until more information becomes available by holding an allowance. This is particularly relevant if abatement decisions involve irreversible investment in abatement technology. Thus, depending on its abatement costs, the firm has the (real) option of either using the allowance for compliance or selling it at the end of the period (e.g., Chao and Wilson 1993; Schennach 2000; Chesney and Taschini 2012). This means that the allowance price should exceed the marginal abatement costs by this real option value. This also explains why, if there is the expectation of an over-allocation of allowances (i.e., more allowances than expected emissions), then a nonzero probability of exceeding the EU ETS cap is sufficient for the allowance price to remain positive (even without the possibility of banking) (Seifert, Uhrig-Homburg, and Wagner 2008; Chesney and Taschini 2012). Clearly, the uncertainty about noncompliance with the cap shrinks toward the end of the compliance period, implying that the (real) option value of allowances is highest at the beginning of the trading phase. If the allowance price includes the (real) option value, then it becomes a poor indicator of current marginal abatement costs, suggesting that deterministic studies have a limited ability to explain allowance price dynamics (Carmona, Fehr, and Hinz 2009).

Hintermann (2012) examines allowance price dynamics during phase I and considers the case where the firm does not undertake abatement. In this case, holding an allowance can be interpreted as exempting the firm from paying a penalty if the cap is exceeded. This makes holding an allowance a binary (i.e., all or nothing) option. Hintermann (2012) finds that an option pricing formula that depends on a penalty for noncompliance and the probability of emissions exceeding the cap explains a significant proportion of the variation in allowance prices in phase I as well as the slowly declining value of allowances toward the end of the phase, even in the face of apparent over-allocation. This suggests that the allowance price during phase I may have been driven by expectations about stochastic emissions rather than marginal abatement costs. To the best of our knowledge, no similar analysis has been conducted for phase II.

\section{Changes in uncertainty over time}

As we have explained, the uncertainty and, therefore, the real-option value shrink toward the end of the trading phase. However, shocks with implications for BAU emissions also alter the degree of uncertainty, suggesting that allowance trading can be characterized by different "regimes." While in certain periods of high uncertainty, a regime might prevail in which the option value describes large parts of the allowance price dynamics; other periods with less uncertainty might reflect a regime in which variations in fundamentals like fuel prices are largely responsible for allowance price dynamics. Lutz, Pigorsch, and Rotfuß (2013) apply an empirical model that explicitly accounts for the possibility that different underlying regimes are at play in determining allowance price dynamics (i.e., a regime-switching model). They distinguish between two regimes, one representing a market characterized by high uncertainty (high price volatility) without a clear price trend and one representing a market characterized by less uncertainty (lower price volatility) and a clear price trend. They show that during periods of less 
uncertainty, market fundamentals explain a large fraction of allowance price dynamics and that the coal price has a negative influence on the allowance price (which was not the case in the earlier [single-regime] base model). Moreover, they show that the high-volatility regime appears to explain price dynamics during the economic recession in 2008 and 2009, and they argue that declining emissions were responsible for the increasing uncertainty about whether the emissions cap was still binding. Chevallier (2011) and Koch (2014) reach similar conclusions, finding that market fundamentals affect allowance price dynamics differently during different time periods and that the link between allowance prices and fundamentals generally became more robust in the second phase compared with the first phase. ${ }^{13}$ These studies suggest that (1) including uncertainty is a promising area for future research on allowance price dynamics and (2) uncertainty varies across time as illustrated by regime-switching models. By allowing for regime switches, these models are less restrictive in their underlying assumptions regarding market behavior than approaches such as cointegration. However, by relying on a purely data-driven identification of different regimes (e.g., volatility), regime-switching models do not provide information concerning the fundamental drivers underlying the switching between regimes. Thus, in order to understand allowance price dynamics, further economic analysis is needed to interpret the results of these models.

\section{Financial analysis of allowance price dynamics}

Allowances are more than a physical commodity traded by emitting firms in order to balance abatement across the EU ETS; they are also a financial commodity traded for profit (or hedging purposes) by other market participants. Thus, in what has become known as the "carbon finance" literature, models from the financial assets and commodity fields are applied to the issue of allowance dynamics. These models also follow a more data-driven approach, focusing in particular on the volatility of allowance prices. Paolella and Taschini (2008) were the first to show that autoregressive models, ${ }^{14}$ which are commonly used in the context of financial asset assessment, are also well suited to describing the heteroscedasticity and unconditional tail distribution in allowance price series. ${ }^{15}$ Benz and Trück (2009), Chevallier (2011), Feng, Zou, and Wei (2011), and Conrad, Rittler, and Rotfuß (2012) investigated and confirmed the partially stochastic behavior of allowance prices when there is clustering of volatility (e.g., periods of high volatility). Daskalakis, Psychoyios, and Markellos (2009) and Gronwald and Ketterer (2012) allow for the possibility of price jumps, and Gronwald, Ketterer, and Trück (2011) estimate the relationship between allowance prices and financial markets by using copulas - a method that relaxes the assumptions concerning the underlying error structure. ${ }^{16}$ Although it is not always straightforward to interpret the results of econometric studies that are not based on theoretical or conceptual models, what is clear from this literature is that even though the scarcity of $\mathrm{CO}_{2}$ emissions allowances is institutionally induced, the allowance market itself appears to function very much like other commodity markets.

\footnotetext{
${ }^{13}$ Instead of a regime-switching model, Koch (2014) uses a smooth transition conditional correlation generalized autoregressive conditional heteroscedasticity (GARCH) model.

${ }^{14}$ In an autoregressive model, the outcome variable (or alternatively, the error term) depends on its own previous values and a random term.

${ }^{15}$ They show that the volatility pattern of EU allowances can be described well by applying GARCH models.

${ }^{16} \mathrm{~A}$ detailed assessment of this rapidly growing literature would be useful but is beyond the scope of this article.
} 


\section{The Challenge of Analyzing Allowance Price Levels}

The somewhat ambiguous empirical results concerning allowance price dynamics may simply reflect inefficiencies in an immature market. However, these results may also be due to the fact that some economic, institutional, and technical factors influence price levels rather than price dynamics. Thus, in this section we examine the empirical literature that either directly or indirectly considers the allowance price level. In particular, we first discuss the general problem of the complex interactions between the allowance price, the quantity of BAU emissions, and the cap, and we then turn to banking and borrowing, other climate policies, such as support for renewable energy and the link to the Kyoto Protocol market, and finally to inefficient trading that results from transaction costs or imperfect competition, all of which have implications for the allowance price level.

\section{Abatement Costs and the Price-Quantity Relationship}

The (deterministic) empirical literature discussed in the previous section assumes a stable relationship between economic fundamentals and the allowance price. However, this assumption is unlikely to hold in general because there is a complex interaction between BAU emissions, abatement quantities, and allowance prices. To provide some intuition, consider the economy-wide marginal abatement cost (MAC) curve that ranks different methods for reducing emissions according to their abatement costs. The marginal abatement technology-that is, the method used to reduce emissions by 1 ton below the cap-depends on the required abatement amount, which is the difference between BAU emissions and the emissions cap. This abatement amount is not fixed but rather depends on a series of variables, including input prices. Suppose that there is a change in the price for natural gas. This may change not only the marginal abatement cost of a given technology but also BAU emissions, due to the substitution of input fuels, thus causing a different abatement technology to be on the margin. This indicates that the marginal effect measured by the studies discussed previously actually reflects two effects that are not individually identified: a relative price effect (a change in the level of the MAC curve) and a quantity effect (a movement along the MAC curve).

Whereas the quantity effect may be negligible when estimating the effect of marginal changes in price fundamentals over a short period of time (assuming that the marginal technology remains the same or at least similar), it does not bode well for our ability to predict the effect of nonmarginal changes. For example, if the EU were considering a 20 percent reduction in the future emissions cap, the studies discussed in previous sections would be of little use in predicting the resulting allowance price, even if some of them include proxies for economic activity in order to control for BAU emissions. This is because the relevant abatement technologies at the new equilibrium may be quite different from those that set the allowance price under the old cap. Empirical studies find that regulatory announcements concerning the stringency of the cap affected allowance prices in phase I (Alberola, Chevallier, and Chèze 2008; Mansanet-Bataller and Pardo 2011; Conrad, Rittler, and Rotfuß 2012) as well as in phase II (Koch et al. 2014; Mansanet-Bataller and Sanin 2014), thus confirming the relevance of quantity effects. However, because market participants' expectations cannot be observed and, moreover, may not be accurate in hindsight, this type of ex post analysis does not allow us to predict the price level in response to a projected change in expected abatement amounts or costs. 
One way to analyze the price-quantity interactions related to abatement is to use numerical simulation models that can produce MAC curves for the entire EU ETS or to compute the effects of different abatement and policy scenarios on the allowance price. For example, increasing the required emission reduction from 20 percent to 30 percent in 2020 (relative to emission levels in 1990) has been estimated to result in an approximate doubling of the allowance price (Saveyn, van Regemorter, and Ciscar 2011; Bosello et al. 2013). Whereas simulation models can, in principle, address the price-quantity relationship of abatement, their results are reliable only to the extent that their assumptions about BAU emissions under various economic conditions and the underlying MAC curve are accurate. However, for both BAU emissions and the underlying MAC curve, reliable data are not available. It is precisely this lack of information about firms' abatement costs and amounts that is the main argument made in favor of a market-based approach to emissions reductions (as opposed to "command-and-control" measures).

\section{Implications of Banking for the Price Level}

The potential to transfer allowances between phases implies that it is the overall long-term cap, rather than the phase-specific cap, that will determine the path of the allowance price. If there is no uncertainty, efficiency implies that firms will abate emissions and bank and borrow allowances so that the allowance price increases at the rate of interest (e.g., Rubin 1996). Banking and borrowing link the allowance price levels in different periods and thus enable firms to smooth their abatement costs over time. The presence of uncertainty does not change the qualitative nature of abatement smoothing, but it can provide additional incentives for banking if firms seek to hedge against emission risk. Without banking and borrowing, hedging becomes more expensive (Schennach 2000; Daskalakis, Psychoyios, and Markellos 2009).

The positive allowance prices that prevailed toward the end of phase II indicate that market participants were banking allowances into phase III because of their awareness of regulatory uncertainty and their expectation of an overall short position in future years. For example, Trück et al. (2015) find that during phase II, firms were insuring themselves against rising allowance prices. ${ }^{17}$ Thus, as discussed earlier, allowance prices reflect both expectations about the future condition of the market and the risk premium required in order to hold allowances.

\section{Other Policies with Implications for the Allowance Price Level}

In general, any policy affecting emissions from installations or sectors participating in the EU ETS can be expected to affect the demand for emission allowances and hence allowance prices. This is particularly true of carbon or energy taxes and policies designed to promote energy efficiency and renewable energy (Fischer and Preonas 2010; Böhringer and Behrens 2015).

As a result of various national policies supporting renewables (e.g., feed-in tariffs or quotas for renewable energy), the share of electricity from renewable sources in the EU-28's gross electricity generation rose from 14.8 percent in 2005, when the EU ETS began, to 25.4 percent in 2013 (Eurostat 2015). A large share of renewable energy still comes from hydropower (43.4

\footnotetext{
${ }^{17}$ Specifically, they show that during phase II, the market changed from initial backwardation to contango. Contango is a situation in which the expected spot price at a future date is below the futures (or forward) price for the same commodity; backwardation describes the opposite situation (i.e., futures prices are below the expected spot price).
} 
percent in 2013), but in 2013, the share of wind power in electricity from renewable sources had reached 27.5 percent, whereas solar power accounted for 10 percent. The remainder comes mainly from biomass and biogas.

Following the EU's decision to set a target of achieving a 20 percent share of energy from renewable sources in energy consumption by 2020 (European Union 2009), a number of studies simulated the effects of this additional target on the EU allowance price. These studies show a wide range of allowance price reductions under different renewable energy support scenarios (e.g., De Jonghe et al. 2009; Traber and Kemfert 2009; Böhringer and Rosendahl 2010). The empirical study by Koch et al. (2014), which examines the extent to which renewable polices can explain the allowance price drop in mid-2008, finds only a very modest effect.

Another policy that affects the allowance price level is the link to the Kyoto Protocol's flexible mechanisms (i.e., the Clean Development Mechanism [CDM] and Joint Implementation [JI]), which allows firms to use a limited number of Kyoto offsets to cover their emissions in lieu of EU allowances. ${ }^{18}$ This policy creates an additional supply of allowances and hence lowers equilibrium price levels. To trace the potential effect of Kyoto offset use on allowance price levels, we again have to rely on numerical simulation studies rather than on econometric analysis. Klepper and Peterson (2006) and Anger (2008) show that allowance prices would be between 30 percent and 50 percent lower with offset use than without offset use.

\section{Transaction Costs and "Thin" Trading}

The strong presence of market intermediaries providing services to firms covered by the EU ETS implies that transaction costs may be important, especially for small firms that do not have specialized units that deal with emissions abatement and allowance trading. Transaction costs, and the resulting low-level—or "thin" — trading, suggest that even when the allowance market is supposed to be in surplus, there may be an insufficient supply of allowances in the short run. In fact, installations with a combined allowance allocation of almost 30 percent of the total EU ETS cap did not engage in any trade through April 2007, effectively removing this quantity of allowances from the market (Hintermann 2015). ${ }^{19}$ Only about 51 percent and 54 percent of German firms covered by the EU ETS were involved in trading in 2009 and 2010, respectively, and almost two-thirds of those that did trade did so only once a year (Heindl 2012). In particular, although small firms tend to hold a surplus of allowances, transaction costs appear to deter them from trading (Jaraite, Convery, and Di Maria 2010; Heindl 2012). If firms with an allowance surplus do not offer to sell their allowances, the resulting market price will be inefficiently high.

Thin trading may cause a market to be inefficient because not all available information is reflected in the price. Montagnoli and de Vries (2010) report persistent allowance price trends during phase I. In an efficient market, such trends should not exist because the price should include all available information, making it impossible to predict the next day's price. However, the results also indicate that efficiency increased during phase II. Crossland, Li, and Roca (2013) investigate the extent to which the EU ETS market can be regarded as "weakly" efficient in the

\footnotetext{
${ }^{18}$ Kyoto offsets are carbon credits generated from CDM (i.e., Certified Emission Reductions [CERs]) and JI (Emission Removal Units [ERUs]) projects. See the EU's Linking Directive (European Union 2004) for details. ${ }^{19}$ Because trading data are kept confidential for 5 years (recently reduced to 3 years), the corresponding figure for phase II is not yet known.
} 
sense that prices are not predictable. Using daily spot prices from 2008 to June 2011, they investigate whether it was possible to earn profits by inferring future prices based on recent price history. They find that, in the short term, allowance prices are characterized by momentum (whereas there is evidence for reversal) in the medium term. ${ }^{20}$ In the long term (up to 12 months), the market again displays under-reaction and the momentum that goes with it. The authors conclude that the EU ETS market is not yet information efficient. Likewise, Daskalakis (2013) reports that simple technical analysis rules (i.e., trading strategies based on momentum and reversal) could have generated substantial risk-adjusted positive returns from 2008 to 2009, whereas there were signs of growing market efficiency starting in 2010. The possibility of systematic profitable trading and the lack of informational efficiency is also shown by Niblock and Harrison (2013) and Aatola, Ollikka, and Ollikainen (2014), who use data from 2008 until 2012 and 2008 until 2010, respectively.

\section{Market Power}

We would expect market power to affect the allowance price level by leading to a price that is either below or above marginal abatement costs. Laboratory experiments indicate that market power may negate some or all of the gains from trade in emission allowance markets (Godby 2002; Cason, Gangadharan, and Duke 2003). Empirical studies of the U.S. sulfur dioxide and nitrous oxide markets find no evidence for market power (for a review, see Montero 2009), but these studies were looking for signs of allowance price depression due to large net buyers. The largest firms in all existing emission allowance markets are electricity generators.

An important difference between the EU ETS and the U.S. allowance markets, which has implications for market power, is the degree of liberalization in the electricity sector and its consequences for cost pass-through. Whereas most U.S. electricity markets are subject to price regulation (such that the electricity price does not respond to short-term changes in input prices), European electricity markets have been liberalized in the sense that the electricity price is determined in a daily auction and thus, at least in theory, is based on marginal production costs. A number of empirical studies find that in many European countries, the full carbon cost is passed through to electricity prices (Sijm et al. 2008; Fabra and Reguant 2014; Hintermann, forthcoming; Fell, Hintermann, and Vollebergh 2015). The combination of free allocation of allowances and cost pass-through can lead to an increase in firms' profits due to the introduction of an allowance market, a phenomenon that has been labeled "windfall profits" in the literature (Sijm, Neuhoff, and Chen 2006; Lise, Sijm, and Hobbs 2010). ${ }^{21}$ Hintermann (2011) shows that the profits of all major EU electricity firms were an increasing function of the allowance price. This is confirmed empirically by Oberndorfer (2009), who finds that in phase I of the EU ETS, the allowance price was positively correlated with the stock prices of European electricity firms, and by Bushnell, Chong, and Mansur (2013), who report a similar result for a larger set of firms. These results suggests that the exercise of market power by

\footnotetext{
${ }^{20}$ Price momentum occurs if price changes on consecutive days are positively correlated. In contrast, price reversal (or price correction) describes a situation where a price decrease is followed by a price increase, and vice versa.

${ }^{21}$ Because allowances constitute a required input for production and can be sold on the market if unused, they will be reflected in the product price like any other valuable input. Cost pass-through is therefore not a sign of market inefficiency; rather it is a sign of a competitiveness. A lack of cost pass-through would indicate the presence of a large markup that can be adjusted to absorb the carbon cost.
} 
electricity firms, which are the only likely candidates to wield such power in the EU ETS and which acted as net allowance buyers, would lead to a higher allowance price level. Similarly, De Feo, Resende, and Sanin (2013) show that strategic competition between upstream (electricity generators) and downstream firms (industry) generally leads to allowance prices exceeding marginal abatement costs.

There can never be conclusive proof of market power because there are always alternative explanations for firms' behavior. However, Hintermann (2015) shows that the largest electricity firms accumulated excess allowance holdings during phase I of the EU ETS, which is consistent with strategic over-purchasing of allowances (and under-abating of emissions) in order to drive up the allowance price. These results suggest that market power is policy relevant, especially in new markets characterized by thin trading, generous free allocation, and high cost passthrough.

\section{Conclusions and Directions for Future Research}

Our review of the literature indicates that substantial progress has been made in increasing our understanding of emission allowance markets, through the use of various approaches, data, and methods. Despite these advances, major gaps remain in our knowledge. In this section, we propose a research agenda aimed at filling these gaps. These research priorities include analyzing the interactions between energy markets and the EU ETS, further examining the drivers of price levels, and developing a more refined model of allowance trading.

\section{Analyzing Interactions between Energy Markets and the EU ETS}

As indicated by the cointegration studies discussed earlier, prices for electricity, fuel inputs, and the allowance price are determined jointly. Unfortunately, current models do not allow for the relationship between prices to change over time. This may be crucial given that marginal generation technologies can be expected to evolve as more renewables enter the system and the cap is continually adjusted. Thus, the development of econometric techniques that allow for a time-varying relationship among codetermined prices would be useful. Moreover, our understanding of the interactions among energy markets can only be as good as our understanding of the functioning of the individual markets themselves. The coal market in particular is poorly understood because the cost for coal that is relevant for power generators may exhibit substantial spatial heterogeneity due to transportation costs. In addition, our understanding of electricity markets and the marginal generating units is far from complete.

\section{Predicting Price Levels}

Our understanding of the relationship between the abatement effort induced by the cap and the resulting price level relies on only a few simulation analyses and thus remains limited, especially concerning the data on allowance price dynamics. This makes it difficult to assess the effect of interactions with alternative EU climate policies, linkages with Kyoto and other markets, and the sensitivity of the price to the setting of future caps, all of which are crucial for improving the design of the EU ETS. Moreover, it prevents economists from speaking authoritatively about whether the price signal provided by the carbon market is approximately right or whether there 
is some deviation between price and (intertemporal) marginal abatement costs that may be explained by factors such as transactions costs, high aversion to engaging in risky abatement decisions under uncertainty, or imperfect competition. Unfortunately, research that improves our understanding of the efficient price level is anything but low-hanging fruit: any effort to understand the price level relies on knowledge of BAU emissions and firms' abatement costs, both of which are unobserved and thus must be modeled. Simulation models that incorporate detailed information about economy-wide abatement opportunities and a realistic representation of firms' abatement and production choices would allow us to develop a better understanding of the relationship between the cap and the resulting price level. In addition, research about transactions costs or the degree of competition could help us to assess the magnitude of price distortions and thus the likely loss in efficiency.

\section{Determining the Efficient Amount of Trading}

Transaction costs appear to play an important role in the EU ETS, especially for smaller firms. Although the amount of allowance trading that takes place is one proxy for the presence of transaction cost, low levels of trading can also be a sign of an efficient initial allocation. To our knowledge, no study has addressed the question of how much trade would be efficient, conditional on an initial allowance distribution and the uncertainty regarding production and abatement decisions. Research on this issue would enable us to infer the importance of transaction costs or other market imperfections from the actual level of trading observed.

\section{Concluding Remarks}

Although the EU ETS has been criticized from an environmental perspective because of its rather low carbon price signal, we believe that the policy has actually performed quite well from an economic point of view. It introduced a single price for emissions, which were previously a free public "bad," and it correctly reflected the substantial oversupply of allowances in both phase I and phase II through a significant price drop. Moreover, the nonzero price toward the end of phase II, despite a nonbinding cap for the phase, reflected expectations of a cap on overall emissions that is binding in the long term, given the opportunity to bank allowances. Remarkably, this development took place during a significant economic crisis that also caused turmoil in other markets. Viewed from this perspective, the EU ETS proved its flexibility with respect to changing economic conditions by reducing the carbon costs during a period of economic stress. This would not have been possible with a rigid command-and-control approach or with a carbon tax, although the latter would probably have achieved a greater reduction in emissions. In addition, because the experience of the first two phases resulted in efficiency-increasing adjustments-for example, the central allocation of allowances and the move toward auctioning in phase III-continued collaboration between research and policy is likely to further improve the functioning of the market.

As is currently being discussed in the EU, the low allowance price could be counteracted through the use of new mechanisms such as price floors or strategic allowance reserves. However, a more direct (and environmentally beneficial) approach would be to tighten the cap, for example, by adjusting the rate at which it is decreased after 2020; because of banking, this should affect the price even today. We would argue that the fact that allowance prices 
turned out to be lower than anticipated (and thus EU climate policy was cheaper than expected) should actually be interpreted as good news rather than a problem. After all, the main economic argument in favor of an emission allowance market is that it delivers a particular emissions goal at least cost.

The EU ETS will likely never become a fully efficient—and therefore idealized—market but rather a compromise between economic theory and political reality. Market efficiency critically depends on the attention firms devote to optimizing their abatement and trading decisions in response to allowance prices. Current allowance price levels may not make the effort worthwhile, but presumably this will change in light of the (likely) stricter future emission targets that will be necessary to achieve the EU's climate goals. Thus, we would argue that although the EU ETS does not function perfectly in every detail, it has nevertheless lived up to many of its expectations and has proven to be a successful application of economic theory to an important environmental issue. 


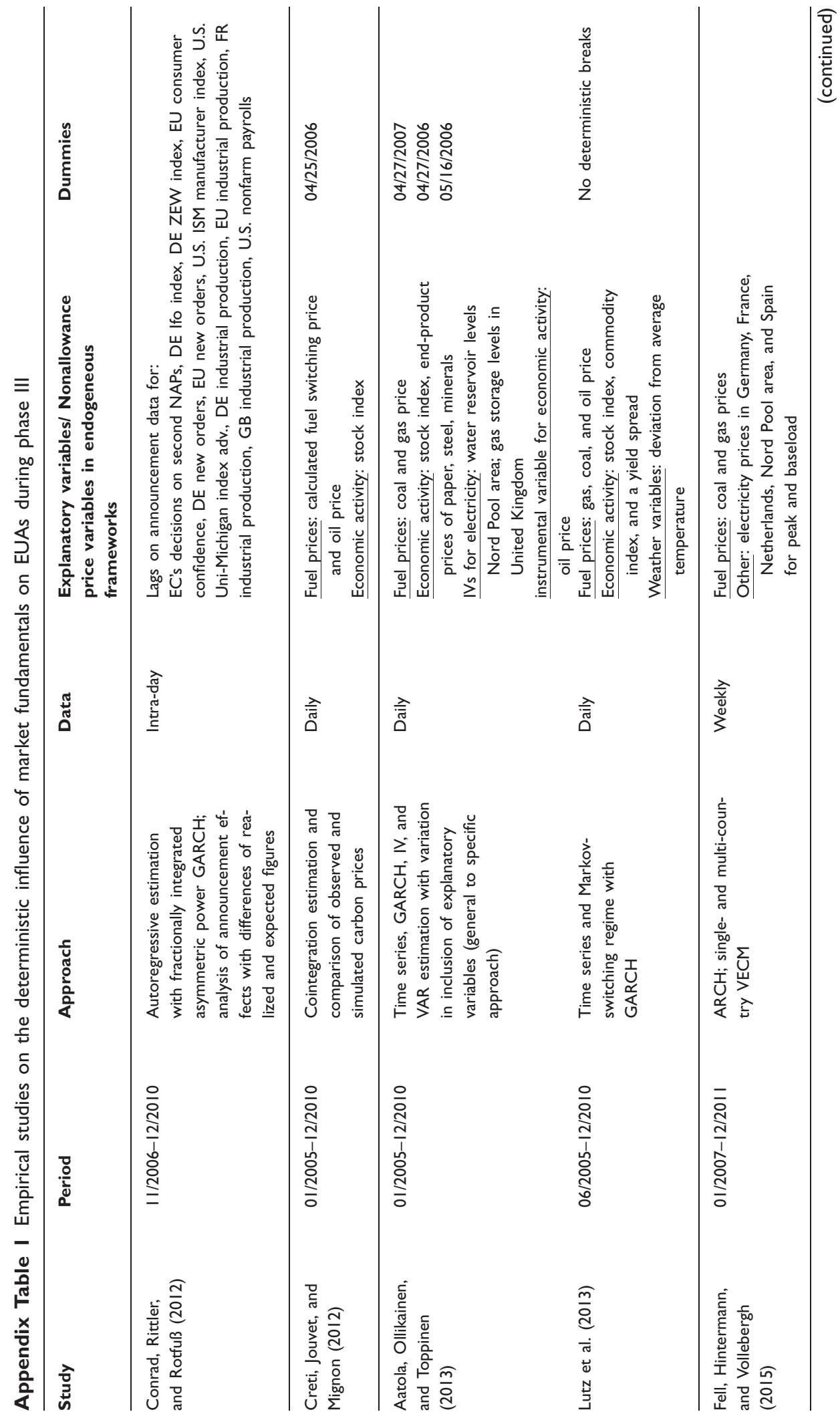




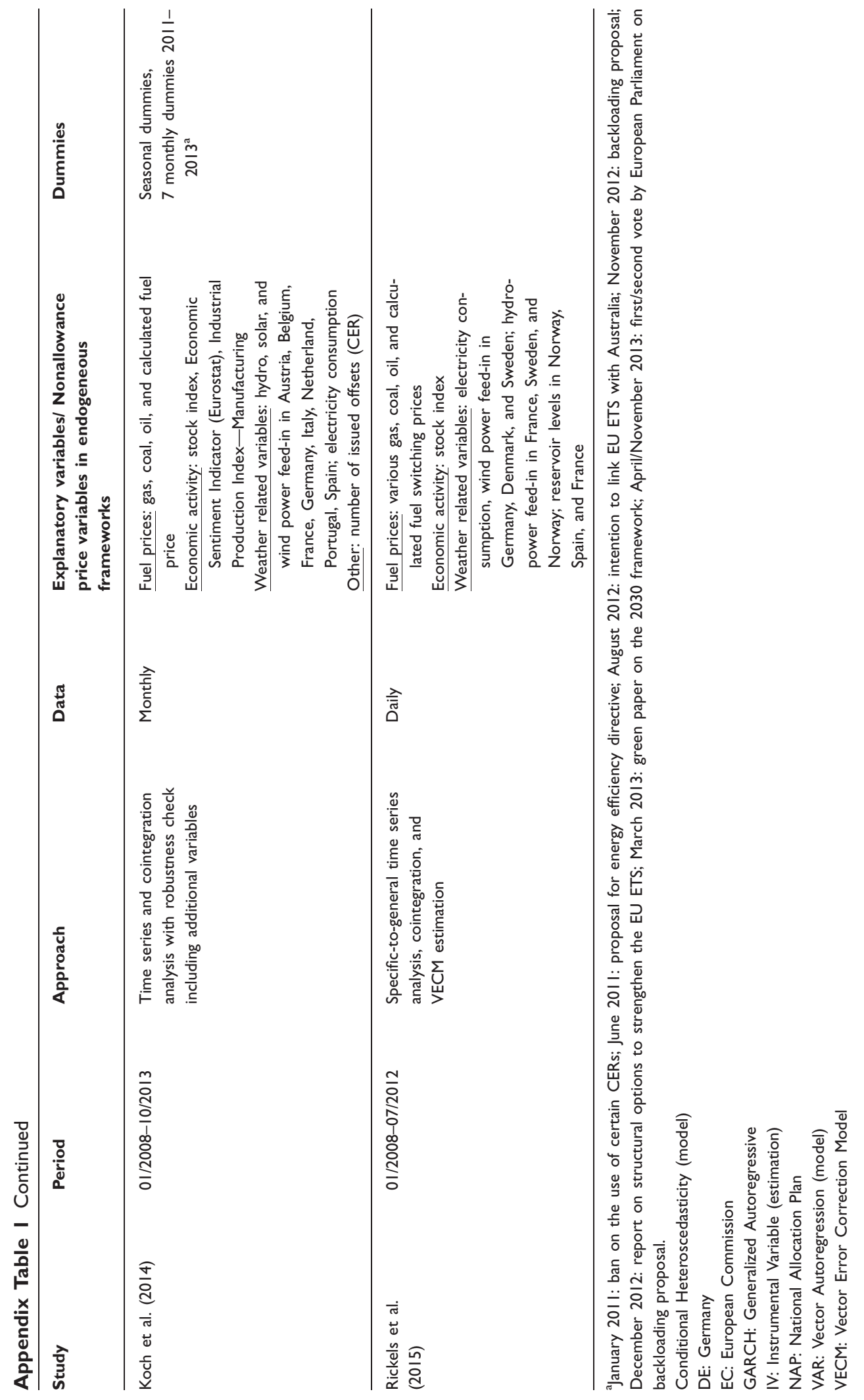




\section{References}

Aatola, Piia, Markku Ollikainen, and Anne

Toppinen. 2013. Price determination in the EU ETS market: Theory and econometric analysis with market fundamentals. Energy Economics 36: 380-95.

Aatola, Piia, Kimmo Ollikka, and Markku Ollikainen. 2014. Informational efficiency of the EU ETS market-A study of price predictability and profitable trading. Journal of Environmental Economics and Policy 3 (1): 92-123.

Alberola, Emilie, Julien Chevallier, and Benoît Chèze. 2008. Price drivers and structural breaks in European carbon prices 2005-2007. Energy Policy 36: 787-97.

Anger, Nils. 2008. Emissions trading beyond Europe: Linking schemes in a post-Kyoto world. Energy Economics 30 (4): 2028-49.

Benz, Eva, and Stefan Trück. 2009. Modeling the price dynamics of $\mathrm{CO}_{2}$ emission allowances. Energy Economics 31 (1): 4-15.

Bertrand, V. 2014. Carbon and energy prices under uncertainty: A theoretical analysis of fuel switching with heterogenous power plants. Resource and Energy Economics 38: 198-220.

Böhringer, C., and Manuela Behrens. 2015. Interactions of emission caps and renewable electricity support schemes. Journal of Regulatory Economics 48 (1): 74-96.

Böhringer, C., and K.E. Rosendahl. 2010. Green promotes the dirtiest: On the interaction between black and green quotas in energy markets. Journal of Regulatory Economics 37: 316-25.

Bosello, Francesco, Lorenza Capagnolo, Carlo Carraro, Fabio Eboil, Ramiro Parrado, and Elisa Protale. 2013. Macroeconomnic impacts of the EU 30\% GHG mitigation target. Nota di Lavoro, Fondazione Eni Enrico Mattei (FEEM).

Bunn, Derek. W., and Carlo Fezzi. 2008. A vector error correction model of interaction among gas, electricity and carbon prices: an application to the cases of Germany and United Kingdom. In Markets for carbon and power pricing in Europe. Theoretical issues and empirical analyses, ed. Francesco Gulli, 145-59. Cheltenham, UK: Edward Elgar Publishing.

Bushnell, James B., Howard Chong, and Erin T. Mansur. 2013. Profiting from Regulation:
Evidence from the European carbon market. American Economic Journal: Economic Policy 5 (4): 78-106.

Carmona, René, Max Fehr, and Juri Hinz. 2009. Optimal Stochastic control and carbon price formation. SIAM Journal on Control and Optimization 48 (4): 2168-90.

Cason, Timothy N., Lata Gangadharan, and Charlotte Duke. 2003. Market power in tradable emission markets: A laboratory testbed for emission trading in Port Phillip Bay, Victoria. Ecological Economics 46: 469-91.

Chao, Hung-Po, and Robert Wilson. 1993. Option value of emission allowances. Journal of Regulatory Economics 5 (3): 233-49.

Chesney, Marc, and Luca Taschini. 2012. The Endogenous price dynamics of emission allowances and an application to option pricing. Applied Mathematical Finance 19 (5): 447-75.

Chevallier, Jullian. 2011. A model of carbon price interactions with macroeconomic and energy dynamics. Energy Economics 33 (6): 1295-1312.

Christiansen, Atle C., Andreas Arvanitakis, Kristian Tangen, and Henrik Hasselknippe. 2005. Price determinants in the EU emission trading scheme. Climate Policy 5 (1): 15-30.

Conrad, Christian, Daniel Rittler, and Waldemar Rotfuß. 2012. Modeling and explaining the dynamics of European Union Allowance prices at high-frequency. Energy Economics 34 (1): 316-26.

Considine, Timothy J. 2000. The impacts of weather variations on energy demand and carbon emissions. Resource and Energy Economics 22: 295-314.

Creti, Anna, Pierre-André Jouvet, and Valérie Mignon. 2012. Carbon price drivers: Phase I versus phase II equilibrium? Energy Economics 34 (1): 327-34.

Crossland, Jarrod, Bin Li, and Eduardo Roca. 2013. Is the European Union Emissions Trading Scheme (EU ETS) informationally efficient? Evidence from momentum-based trading strategies. Applied Energy 109: 10-23.

Daskalakis, George. 2013. On the efficiency of the European carbon market: New evidence from phase II. Energy Policy 54: 369-75. 
Daskalakis, George, Dimitris Psychoyios, and Raphael N. Markellos. 2009. Modeling $\mathrm{CO}_{2}$ emission allowance prices and derivatives: Evidence from the European trading scheme. Journal of Banking and Finance 33 (7): 1230-41.

De Feo, Giuseppe, Joana Resende, and MariaEugenia Sanin. 2013. Emission permits trading and downstream strategic market interaction.

Manchester School 81 (5): 780-802.

De Jonghe, Cederik, Erik D. Delarue, Ronnie Belmanns and William D'haseleer. 2009. Interactions between measures for the support of electricity from renewable energy sources and $\mathrm{CO}_{2}$ mitigation. Energy Policy 37 (11): 4743-52.

Delarue, Erik D., A. Denny Ellerman, and William D. D'haeseleer. 2010. Robust MACCs? The topography of abatement by fuel switching in the European power sector. Energy 35 (3): 1465-75. Ellerman, A. Denny, Claudio Marcantonini, and Aleksandar Zaklan. 2016. The European Union Emissions Trading System: Ten years and counting. Review of Environmental Economics and Policy 10 (1): 89-107.

Eurostat. 2015. Statistics explained. http//ec.europe. eu/Eurostat/statistics-explained/.

European Union. 2004. Directive 2004/101/EC of the European Parliament and of the Council amending Directive 2003/87/EC establishing a scheme for greenhouse gas emission allowance trading within the community, in respect of the Kyoto Protocol's project mechanisms. 2004/ 101/EC.

- 2009. Directive 2009/28/EC of the European Parliament and of the Council of April 232009 on the promotion of the use of energy from renewable sources and amending and subsequently repealing Directives 2001/77/EC and 2003/ 30/EC.

Fabra, Natalia, and Mar Reguant. 2014. Passthrough of emissions costs in electricity markets. American Economic Review 104 (9): 2872-99.

Fell, Harrison. 2010. EU-ETS and Nordic Eeectricity: A CVAR analysis. Energy Journal 31 (2): $1-25$.

Fell, Harrison, Beat Hintermann, and Herman R. J. Vollebergh. 2015. Estimation of carbon cost passthrough in electricity markets. Energy Journal 36 (4): 61-83.
Feng, Zhen-Hua, Le-Le Zou, and Yi-Ming Wei. 2011. Carbon price volatility: Evidence from EU ETS. Applied Energy 88 (3): 590-98.

Fischer, C., and L. Preonas. 2010. Combining policies for renewable energy: Is the whole less than the sum of its parts? International Review of Environmental and Resource Economics 4: 51-92. Godby, Robert. 2002. Market power in laboratory emission permit markets. Environmental and Resource Economics 23 (3): 279-318.

Gronwald, Marc, and Janina Ketterer. 2012. What moves the European carbon market? Insights from conditional jump models. CESifo Working Paper No. 3795. Munich: Ifo Institute.

Gronwald, Marc, Janina Ketterer, and Stefan Trück. 2011. The relationship between carbon, commodity and financial markets: A Copula analysis. Economic Record 87: 105-24.

Heindl, Peter. 2012. Transaction costs and tradable permits: Empirical evidence from the EU Emissions Trading Scheme. ZEW Discussion Paper 12-021, Centre for European Economic Research, Mannheim.

Heindl, Peter, and Andreas Löschel. 2012. Designing emissions trading in practice-General considerations and experiences from the EU Emissions Trading Scheme (EU ETS). ZEW Discussion Paper 12-009, Centre for European Economic Research, Mannheim

Hintermann, Beat. 2010. Allowance price drivers in the first phase of the EU ETS. Journal of Environmental Economics and Management 59 (1): $43-56$.

- 2011. Market power, permit allocation and efficiency in emission permit markets. Environmental and Resource Economics 49 (3): $327-49$.

2012. Pricing emission permits in the absence of abatement. Energy Economics 34: 1329-40. . 2015. Market power in emission permit markets: Theory and evidence. Environmental and Resource Economics 10.1007/s10640-015-9939-4.

Forthcoming. Pass-through of $\mathrm{CO}_{2}$ emission costs to hourly electricity prices in Germany. Journal of the Association of Environmental and Resource Economists.

Jūratė Jaraite, Frank Convery, and Corrado Di Maria. 2010. Transaction costs for firms in the EU 
ETS: Lessons from Ireland. Climate Policy 10 (2): 190-215.

Kanen, Joost L. M. 2006. Carbon trading and pricing. London: Environmental Finance Publications. Klepper, Gernot, and Sonja Peterson. 2006. Emissions trading, CDM, JI and more-The climate strategy of the EU. Energy Journal 27 (2): $1-26$.

Koch, Nicolas. 2014. Dynamic linkages among carbon, energy and financial markets: A smooth transition approach. Applied Economics 46 (7): 715-29.

Koch, Nicolas, Sabine Fuss, Godefroy Grosjean, and Ottmar Edenhofer. 2014. Causes of the EU ETS price drop: Recession, CDM, renewable policies or a bit of everything?-New evidence. Energy Policy 73: 676-85.

Lise, Wietze, Jos Sijm, and Benjamin F. Hobbs. 2010. The Impact of the EU ETS on prices, profits and emissions in the power sector: Simulation results with the COMPETES EU20 model. Environmental and Resource Economics 47 (1): 23-44.

Lo Prete, C., and C. S. Norman. 2013. Rockets and feathers in power futures markets? Evidence from the second phase of the EU ETS. Energy Economics 36: 312-21.

Lutz, Benjamin L., Uta Pigorsch, and Waldemar Rotfuß. 2013. Nonlinearity in cap-and-trade systems: The EUA price and its fundamentals. ZEW Discussion Paper, 13-001, Centre for European Economic Research, Mannheim.

Mansanet-Bataller, Maria, and Angel Pardo. 2011. Impacts of regulatory announcements of $\mathrm{CO}_{2}$ prices. Journal of Energy Markets 2 (2): 75-107. Mansanet-Bataller, Maria, and Maria Eugenia Sanin. 2014. Regulation as a determinant of EUA prices. Energy Studies Review 1 (1): 66-89.

Martin, Ralf, Mirabelle Muûls, and Ulrich J. Wagner. 2016. The impact of the European Union Emissions Trading Scheme on regulated firms: What is the evidence after ten years? Review of Environmental Economics and Policy 10 (1): 129-48.

Montagnoli, Alberto, and Frans P. de Vries. 2010. Carbon trading thickness and efficiency. Energy Economics 32: 1331-36.

Montero, Juan-Pablo. 2009. Market power in pollution permit markets. MIT Center for Energy and
Environmental Policy Research Working Paper No. 09-006. Cambridge, MA: Massachusetts Institute of Technology.

Montgomery, W. David. 1972. Markets in licenses and efficient pollution control programs. Journal of Economic Theory 5: 395-418.

Niblock, Scott J., and Jennifer L. Harrison. 2013. Carbon markets in times of VUCA: A weak-form efficiency investigation of the phase II EU ETS. Journal of Sustainable Finance \& Investment 3 (1): 38-56.

Oberndorfer, Ulrich. 2009. EU emission allowances and the stock market: Evidence from the electricity industry. Ecological Economics 68 (4): 1116-26.

Paolella, Marc S., and Luca Taschini. 2008. An econometric analysis of emissionallowances prices. Journal of Banking and Finance 32 (10): 2022-32.

Pettersson, Fredrik, Patrik Söderholm, and Robert Lundmark. 2013. Fuel switching and climate and energy policies in the European power generation sector: A generalized Leontief model. Energy Economics 34 (4): 1064-73.

Rickels, Wilfried, Dennis Görlich, and Sonja Peterson. 2015. Explaining European Emission Allowance Price Dynamics: Evidence from Phase II. German Economic Review 16 (2): 181-202.

Rubin, Jonathan D. 1996. A model of intertemporal emission trading, banking, and borrowing. Journal of Environmental Economics and Management 31: 269-86.

Saveyn, Bert, Denis van Regemorter, and Juan Carlos Ciscar. 2011. Economic analyses of the climate pledges of the Copenhagen Accord for the $\mathrm{EU}$ and other major countries. Energy Economics 33: S34-S40.

Schennach, Susanne M. 2000. The economics of pollution permit banking in the context of Title IV of the 1990 Clean Air Act Amendments. Journal of Environmental Economics and Management 40 (3): 189-210.

Schernikau, Lars. 2010. The renaissance of steam coal. Economics of international coal trade. Berlin: Technical University of Berlin.

Seifert, Jan, Marliese Uhrig-Homburg, and Michael Wagner. 2008. Dynamic behavior of $\mathrm{CO}_{2}$ spot prices. Journal of Environmental Economics and Management 56 (2): 180-94. 
Sijm, Jos, Karsten Neuhoff, and Yihsu Chen. 2006. $\mathrm{CO}_{2}$ cost pass through and windfall profits in the power sector. Climate Policy 6 (1): 49-72.

Sijm, Jos, S. Hers, Lise Wietze, and B. Wetzelaer. 2008. The impact of the EU ETS on electricity prices. Final report to DG Environment of the European Commission.

Tietenberg, Thomas H. 1985. Emissions trading. An exercise in reforming pollution policy. Washington, DC: Resources for the future.

Traber, Thure, and Claudia Kemfert. 2009. Impacts of the German Support for Renewable Energy on Electricity Prices, Emissions, and Firms. Energy Journal 30 (3): 155-78.
Trück, Stefan, Wolfgang Hardle Rafal, and Weron 2015. The Relationship between spot and futures $\mathrm{CO}_{2}$ emission allowance prices in the EU-ETS. In Emissions trading as a policy instrument: Evaluation and prospects, eds., M. Gronwald and B.

Hintermann, 183-212. Cambridge, MA: MIT Press. Zaklan, Aleksandar, Astrid Cullmann, Anne Neumann, and Christian von Hirschhausen. 2012. The globalization of steam coal markets and the role of logistics: An empirical analysis. Energy Economics 34 (1): 105-16.

Zhang, Yue-Jun, and Yi-Ming Wei. 2010. An overview of current research on EU ETS: Evidence from its operating mechanism and economic effect. Applied Energy 87 (6): 1804-14. 